
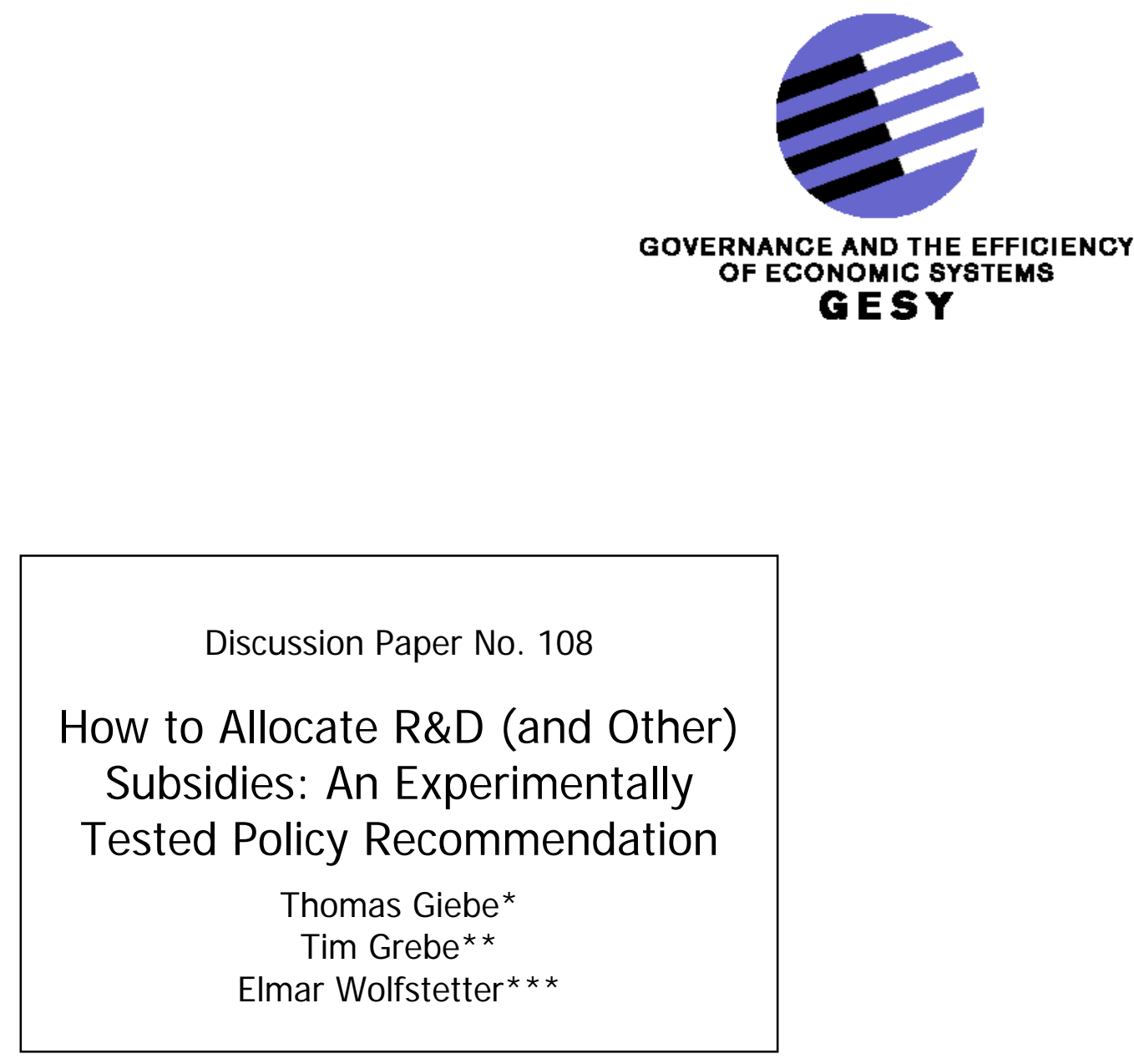

October 2005

*Thomas Giebe, Institut für Wirtschaftstheorie I, Humboldt.Universität zu Berlin Spandauer Str. 1, 10099 Berlin, Germany. giebe@wiwi.hu.berlin.de

**Tim Grebe, Institut für Wirtschaftstheorie I, Humboldt.Universität zu Berlin Spandauer Str. 1, 10099 Berlin, Germany. grebe @wiwi.hu.berlin.de

***Elmar Wolfstetter, Institut für Wirtschaftstheorie I, Humboldt.Universität zu Berlin Spandauer Str. 1, 10099 Berlin, Germany.wolfstetter@wiwi.hu.berlin.de

Financial support from the Deutsche Forschungsgemeinschaft through SFB/TR 15 is gratefully acknowledged. 


\title{
How tO AllOCATE R\&D (AND OTHER) SUbSIDIES: AN EXPERIMENTALly TeSTED POLICY RECOMMENDATION ${ }^{1}$
}

\author{
Thomas Giebe TIM Grebe $\quad$ Elmar WolfstetTer \\ Institut für Wirtschaftstheorie I, Humboldt-Universität zu Berlin \\ Spandauer Str. 1, 10099 Berlin, Germany \\ Email: giebe/grebe/wolfstetter@wiwi.hu-berlin.de
}

OCTOBER 2005

\begin{abstract}
${ }^{1}$ This work emerged from a research project for the German Federal Ministry of Economics and Technology, which was carried out jointly with GIB-Association for Innovation Research and Consultancy Ltd. and Fraunhofer ISI. We thank Radosveta Ivanova-Stenzel, Werner Güth, Marzia Romanelli, and the members of the Strategic Interaction Group at the Max Planck Institute for Research into Economic Systems at Jena for helpful comments. Financial support by the Deutsche Forschungsgemeinschaft (SFB Transregio 15: "Governance and Efficiency of Economic Systems") is gratefully acknowledged.
\end{abstract}




\begin{abstract}
This paper evaluates how R\&D subsidies to the business sector are typically awarded. We identify two sources of inefficiency: the selection based on a ranking of individual projects, rather than complete allocations, and the failure to induce competition among applicants in order to extract and use information about the necessary funding. In order to correct these inefficiencies we propose mechanisms that include some form of an auction in which applicants bid for subsidies. Our proposals are tested in a simulation and in controlled lab experiments. The results suggest that adopting our proposals may considerably improve the allocation.
\end{abstract}

JEL classification: D44, D45, H25, O32, O38

Keywords: Research, Subsidies, Experimental Economics 
"Public money is like holy water; everyone helps himself to it."

Italian Proverb

\section{INTRODUCTION}

R\&D subsidies to the business sector are an important part of research policy. For example, the German government spends roughly $€ 2.2$ billion per year or $5 \%$ of its total R\&D expenditures for supporting industry R\&D. 1 Typically, R\&D support is organized in programs which pursue a specific aim such as promoting job creation in particular regions or improving the research intensity in a particular industry. Some of these programs offer grants, others provide loans at subsidized interest rates or funding in return for a profit share. Most programs are geared to support small and medium sized businesses (SMEs) or cooperative projects involving SMEs.

In this paper, we focus on programs that offer non-refundable grants. This is a very common form of subsidization. In most of these programs the allocation of funds is organized in competitions, as follows. ${ }^{2}$ Applicants submit written proposals to a program managing institution at some due date; in these proposals they describe a specific project for which they want to receive a grant. These proposals are pre-screened and short-listed, and then evaluated by a team of experts on the basis of their scientific and economic merit. Based on the expert advice, a committee grades projects, using a small set of grades such as $A, B$, and $C$. And the committee selects projects in the order of the assigned grades, down from $A$ to $C$, until the available budget is exhausted. Thereby, each funded project receives a subsidy equal to a predetermined percentage of the scheduled refundable project cost. ${ }^{3}$

Whilst the focus of this paper is on R\&D support policy in Germany, we note that similar attribution procedures are applied in numerous other countries. As an example, information on similar programs in the U.K, the U.S. and in Israel can be found in Binks et al. (2003) and Trajtenberg (2002).

In the present paper we will not debate the merit of directly subsidizing firms' R\&D activities. ${ }^{4}$ However, we object to the way in which firms' projects are selected and subsidies are determined. As we will argue, neither the selection procedure nor the competition based on quality criteria only, is efficient. In this paper, we propose better ways to achieve the given purpose.

\footnotetext{
${ }^{1}$ see Czarnitzki and Fier (2001).

${ }^{2} \mathrm{~A}$ detailed description and analysis of some of the programs applied in Germany can be found in e.g. Blum et al. (2001), Becker et al. (2004) and Eickelpasch and Fritsch (2005).

${ }^{3}$ Typically only part of the project cost, such as personnel cost, are eligible for subsidies. A frequently employed rule is the "match grant" where $50 \%$ of the refundable project cost are reimbursed.

${ }^{4}$ Some researchers, such as Martin and Scott (2000), have suggested that one should subsidize venture capitalists rather than firms. Other researchers investigate into the overall effectiveness of R\&D subsidies in promoting research in private enterprises. See e.g. García-Quevedo (2005) for an international survey and Czarnitzki and Licht (2005) for a survey on the effects of R\&D subsidies in Germany.
} 
Specifically, we see two main deficiencies and propose to modify the currently used attribution procedure in two ways.

1. Funding the best projects until the budget is exhausted is inefficient. Instead, the selection should be based on a ranking of complete allocations of funds.

2. Funding the selected projects at a predetermined percentage of project cost is inefficient. Instead, one should induce applicants to compete by lowering their requests for funding.

In order to achieve these objectives, we propose to base the selection of projects on a ranking of allocations, and to embed that selection rule in a simple auction mechanism. The development of an auction-like mechanism for awarding subsidies has been suggested by Blum et al. (2001) and Blum and Kalus (2003). In that mechanisms firms compete with their requests for funding, which gives them an incentive to reveal private information and lower their demand for subsidies. In Blum and Kalus (2003), it is proposed to use an auction similar to an English Auction. In this paper, we develop this idea further by designing two specific auction mechanisms, one sealedbid and one open descending-bid mechanism, and test these mechanisms by means of a simulation and a controlled lab experiment.

The plan of the paper is as follows. In section 2 we discuss selection rules and show why one should select on the basis of a ranking of complete allocations. In Section 3, we explain two specifications of an auction mechanism and the relation of our auction problem to the existing experimental and theoretic literature. Section 4 evaluates the proposed selection rule by a Monte Carlo simulation. Section 5 describes the design of a lab experiment to test the two auction mechanisms. Section 6 summarizes the results of the experiment. Section 7 summarizes and Section 8 discusses the implications of our proposals.

\section{RANKING PROJECTS VS. RANKING ALLOCATIONS}

We analyze the following allocation problem: The government has offered an R\&D subsidy program that grants subsidies according to some rule, within the limits of a given budget. Applicants have submitted project proposals, and the selection committee has evaluated them and has short-listed a set of projects $P:=\{1, \ldots, n\}$ which are judged as eligible for funding. Project $i$ shall receive a subsidy of $s_{i}$ if selected. The selection committee has to choose a subset of projects that shall be funded within the limits of the given budget $\mathcal{B}$.

The standard selection rule is based on a ranking of individual projects, from the set of short-listed projects, as follows: 1) Each project is assigned a grade from a given set of grades (for the moment one may assume that each project has a distinct grade). 2) Projects are selected, moving from 
highest to lower grades, until the given budget is exhausted. As a result, no lower grade project ever crowds out a higher grade. This may seem to be a desirable property; however, it is generally not optimal.

As an illustration consider the example of four projects, $P=\left\{P_{1}, \ldots, P_{4}\right\}$, which require the following subsidies if selected: $s=\{100,50,50,50\}$ and a budget of 150. Suppose the selection committee has the preference order $P_{1} \succsim P_{2} \succsim P_{3} \succsim P_{4}$. Then the selection based on the ranking of individual projects leads to the selection of projects $\left\{P_{1}, P_{2}\right\}$. However, if $\left\{P_{2}, P_{3}, P_{4}\right\}$ is preferred to $\left\{P_{1}, P_{2}\right\}$, it would be better to select $\left\{P_{2}, P_{3}, P_{4}\right\}$ since that allocation is also feasible at the given budget. This indicates that the selection based on the ranking of individual projects leads astray, because it does not take into account that a high-grade project may crowd out several lower-grade projects which are inferior in pairwise comparisons, but lead to a superior allocation. Indeed, that selection is equivalent to preferring every single higher-grade to any number of lower-grade projects.

Therefore, as a first step towards achieving a better selection process, the selection committee has to learn how to think in terms of complete allocations, and apply the following selection rule: ${ }^{5}$

PROPOSAL 1 Select projects based on a ranking of allocations, rather than based on a ranking of projects, as follows: 1) Determine all allocations that are feasible (can be funded with the given budget). 2) Rank all feasible allocations and select the projects that are part of the highest ranking feasible allocation.

In practical application this procedure may be fairly complex, since the number of allocations increases exponentially with the number of projects. Therefore, we recommend sticking to a fixed grading system, as it is typically used in the current system, consisting of at most three grades, such as $\{A, B, C\}$. Such a grading system treats projects of the same grade as perfect substitutes. We were also told by program managers that employing more than two or three grades was not sensible because this would only suggest a degree of precision that cannot be achieved. In addition one may use constant equivalence rules that state how many higher-grade projects are equivalent to one lower-grade project. Using such constant equivalence rules corresponds to assuming linear indifference curves in the commodity resp. grade space. For example, for the grade set $\{A, B, C\}$ the equivalence rules $(e(b), e(c))$ state the number of grade- $A$ projects that are equivalent to one grade- $B$, resp. grade- $C$, project. We also employ this practical device in our lab experiments which are described in section 5 .

Our above proposal requires neither the use of grades nor of constant equivalence rules. Using these makes the selection simple. However, it is only advisable if the underlying assumptions are justified as an approximation.

As a practical advice, one may consider to prespecify the grade set and the fixed equivalence rules, and ask those who assess the quality of projects only to assign grades, taking into account the given equivalence rules.

\footnotetext{
${ }^{5}$ To an economist, this proposal is fairly obvious. However, in our experience, program managers are not aware of the flaws of the current selection procedure.
} 
FORMAL STATEMENT OF THE ALLOCATION RANKING PROBLEM We conclude this section with a precise statement of the allocation ranking problem. The notation introduced here will also be used to describe our auction mechanisms.

For this purpose, let $P:=\{1, \ldots, n\}$ be the finite set of short-listed projects, and $\mathcal{A}$ the set of subsets (i.e., the power set) of $P$. Therefore, $\mathcal{A}$ is the set of all conceivable allocations from which the committee has to select one, under some feasibility constraint.

Ideally, the selection committee has a complete preference ranking, “ $\succsim$ ”, of all allocations, such that for all $a, a^{\prime} \in \mathcal{A}$ one has $a \succsim a^{\prime}$ or $a^{\prime} \succsim a$ that is reflexive and transitive. Such a preference ranking defined on a set of finite alternatives can be represented by an (ordinal) utility function, $U: \mathcal{A} \rightarrow \mathbb{R}$ such that $\forall a, a^{\prime} \in \mathcal{A}: U(a) \geq U\left(a^{\prime}\right) \Longleftrightarrow a \succsim a^{\prime}$.

The promised subsidy for project $i$, if it is part of the allocation, is denoted by $s_{i}$.

The choice of allocation based on a ranking of individual projects (as in the status quo procedure) is denoted by $a^{s}$ and the choice of allocation according to Proposal 1 is denoted by $a^{p}$. Thus, $a^{p}$ is the maximizer of $U(a)$ over all feasible allocations that can be funded with the given budget $\mathcal{B}$ :

$$
a^{p} \in \underset{a \in \mathcal{A}}{\arg \max }\left\{U(a) \mid \sum_{i \in a} s_{i} \leq \mathcal{B}\right\} .
$$

As mentioned before, committees often employ a grading scheme as a simplifying device. Together with an equivalence rule of grades this may lead to a pragmatic construction of a utility function, as follows.

Let $G:=\left\{g_{1}, \ldots, g_{m}\right\}$ be a set of grades, such as $G=\{A, B, C\}$ where $g_{1}>g_{2}>\ldots>g_{m}$. Then, the first step is to grade all projects, which is summarized by $\Gamma: P \rightarrow G$. Using $\Gamma$, one then computes, for each allocation, its frequency distribution of grades, denoted by $\gamma: \mathcal{A} \rightarrow \mathbb{N}^{m}$.

Next, the committee chooses an equivalence rule $e: G \rightarrow \mathbb{R}^{m}$, where $e\left(g_{j}\right)$ states the number of grade- $g_{1}$ projects that are equivalent to one grade- $g_{j}$ project. Of course, $1=e\left(g_{1}\right)>e\left(g_{2}\right)>\cdots>e\left(g_{m}\right)$.

Combining the grading scheme and the equivalence rule, one finds the utility function

$$
U(a):=\sum_{j=1}^{m} \gamma_{j}(a) e\left(g_{j}\right) .
$$

$U(a)$ has a nice interpretation: let $a^{\prime}$ be an allocation that contains $U(a)$ grade- $g_{1}$ projects and no other projects; then, the committee's preference order exhibits $a^{\prime} \sim a$.

Also notice that the selection based on ranking individual projects can be viewed as a special case of a ranking based on allocations if and only if the project manager has lexicographic preferences, which give first priority to grade $g_{1}$ projects, second priority to grade $g_{2}$ projects, etc.. 


\section{TWO AUCTION MECHANISMS}

We now turn to the second deficiency of the current subsidization policy: the funding of projects at a predetermined percentage of the refundable project cost. Generally this leads to excessive funding of those who are selected, and thus tends to exclude other valuable projects.

Typically, the selection committee cannot know the amount of funding needed to induce the applicant to carry out its project. They only know that this unknown amount is not greater than $s_{i}$, the amount of subsidy that would be granted according to the current rules ${ }^{6}$. This suggests that one can reduce funding without losing valuable projects. It requires the design of a mechanism that induces applicants to compete by lowering their request for funding.

We propose two such mechanisms: one sealed-bid and one open descendingbid mechanism. Both mechanisms are auction-like in the sense that applicants compete with their requests for funding which can be viewed as their bids and the mechanism selects the best allocation that can be funded with the given budget.

To carry out their project as stated in the application, the applicant requires a certain amount of subsidization, which is denoted by $z_{i}$. The fact that $z_{i}$ is private information motivates the use of the auction mechanisms. An auctioneer knowing $z_{i}$ could directly implement the optimal allocation, namely

$$
a^{o} \in \underset{a \in \mathcal{A}}{\arg \max }\left\{U(a) \mid \sum_{i \in a} z_{i} \leq \mathcal{B}\right\},
$$

by funding each applicant in the allocation exactly at the required level to implement its project.

Each applicant now submits a bid $b_{i}$ according to one of the following two mechanisms.

\subsection{Sealed-Bid Mechanism}

The sealed-bid mechanism is characterized by the following allocation and pricing rules:

1. Each applicant $i \in P$ makes a sealed bid $b_{i} \in\left[0, s_{i}\right]^{7}$, without knowing the bids made by others. Bids are requests for funding.

2. On the basis of the given bids $b=\left(b_{1}, \ldots, b_{n}\right)$, the mechanism

\footnotetext{
${ }^{6}$ An applicant who requires more than $s_{i}$ would not apply because he would not be able to carry out the project as stated in the application. In most programs there is close monitoring by program managers such that applicants are not able to change the nature of their project significantly once the application is accepted.

${ }^{7}$ Notice that the maximum bid is set to $s_{i}$. This maximum bid restriction is discussed in Section 3.3.
} 
(a) selects the allocation, $a^{*}$, that solves the maximization problem ${ }^{8}$

$$
a^{*} \in \underset{a \in \mathcal{A}}{\arg \max }\left\{U(a) \mid \sum_{i \in a} b_{i} \leq \mathcal{B}\right\} .
$$

(b) pays a subsidy equal to $b_{i}$ if $i \in a^{*}$ and equal to zero otherwise.

\subsection{Open Descending-Bid Mechanism}

The second mechanism is an open descending-bid auction which consists of several "rounds."

1. Each applicant $i$ faces his own price clock that starts at $s_{i}$. Subsequently, the reading of the price clock declines at rate $\Delta$ in each round.

2. The final bid $b_{i}$ of applicant $i$ is the price where he stops his price clock. After stopping the price clock, applicants are not allowed to lower their bid any further. Applicants can see others' price clocks at any time and can always observe if other applicants have stopped in an earlier round.

3. On the basis of the given bids $b=\left(b_{1}, \ldots, b_{n}\right)$, the mechanism selects the allocation as in the sealed-bid mechanism.

PROPOSAL 2 Use either the sealed-bid or the open descending-bid mechanism. This induces competition for funding.

\subsection{Maximum Bid Restriction}

It is advisable to structure the auction in such a way that its outcome can never be inferior to the outcome that would be reached if one would apply Proposal 1 only, without an auction.

This can be achieved by setting individual maximum bids equal to the subsidy rates $s_{i}$ that would be granted according to the current subsidy rules. Therefore, we propose

Proposal 3 If one uses one of the auction mechanisms, set each applicant's maximum bid equal to the subsidy rate that would be granted according to the current subsidy rules (which we denoted by $s_{i}$ ).

In policy advice one should always try to make proposals that cannot yield an outcome inferior to that achieved by the status quo practice. To achieve this is the only purpose of Proposal 3.

Notice that we already incorporated this proposal in the two auction mechanisms described before.

\footnotetext{
${ }^{8}$ If $a^{*}$ is not unique, it selects the allocation that minimizes $\sum_{i \in a^{*}} b_{i}$; if the result is still not unique, it selects at random.
} 


\subsection{An Example of an Open Descending-Bid Auction}

The following example illustrates the working of the open descending-bid mechanism (see Table 1). It assumes a budget of 70, a bidding decrement of 5 , and five applicants (1 to 5). Projects are substitutes and have the utilities stated in column 2. The associated minimum subsidies $\left(z_{i}\right)$ are stated in column 3, and the subsidies $s_{i}$ that would be granted if no auction were used in column 4 . Bold numbers indicate which applicants would be part of the allocation if the auction would stop at the current round. If no auction were used, the allocation would be $\{1,2\}$, with total utility 100 .

\begin{tabular}{c|cccccc}
\hline \hline Applicant & Utility & $z_{i}$ & $s_{i}$ & Round 1 & Round 2 & Round 3 \\
\hline 1 & 53 & 20 & $\mathbf{4 0}$ & 35 & 30 & $\mathbf{2 5}$ \\
2 & 47 & 20 & $\mathbf{3 0}$ & $\mathbf{2 5}$ & $\mathbf{2 0}$ & $\mathbf{2 0}$ \\
3 & 38 & 20 & 30 & $\mathbf{2 5}$ & $\mathbf{2 0}$ & 20 \\
4 & 37 & 10 & 25 & $\mathbf{2 0}$ & $\mathbf{1 5}$ & $\mathbf{1 0}$ \\
5 & 35 & 15 & 25 & 20 & $\mathbf{1 5}$ & $\mathbf{1 5}$ \\
\hline$a$ & & & $\{1,2\}$ & $\{2,3,4\}$ & $\{2,3,4,5\}$ & $\{1,2,4,5\}$ \\
$U(a)$ & & & 100 & 122 & 157 & 172 \\
\hline \hline
\end{tabular}

Table 1: Example of an Open Auction

This example assumes that all applicants stop their price clocks at round three. The auction ends with allocation $a^{*}=\{1,2,4,5\}$. The example illustrates how an applicant, in the course of an auction, can be crowded out at some round and return to the allocation in a later round. The last row of the table states the total utility of the respective allocations. The optimal allocation is $\{1,2,3,4\}$, and the maximum feasible utility is 175 .

\subsection{The nature of the auction problem}

The present auction problem can be viewed as that of a multi-unit procurer (auctioneer) facing several single-unit suppliers (bidders), where both the auctioneer and bidders are budget-constrained. Moreover, the supplied goods can be viewed as heterogeneous. To the best of our knowledge such a problem has not been studied before, neither in the theoretical nor in the experimental auctions literature. There is a literature on standard singleand multi-unit auctions with budget constrained bidders (see Che and Gale (1998), Laffont and Robert (1996) for the single-unit case, and Benoît and Krishna (2001) for the multi-unit case). However, a budget constrained auctioneer, which is of crucial importance in the present framework, has never been considered. Its game theoretic analysis raises a number of technical complications. 


\section{MONTE CARLO SIMULATION}

The simulation is designed to assess the benefit of switching from a selection based on an ranking of individual projects to a global decision procedure that is based on a ranking of allocations, as recommended in Proposal 1. Notice that adding an auction mechanism, as proposed in Proposal 2, gives rise to further improvements.

The simulation is designed as follows: We consider a pool of 250 projects and a given budget of $\mathcal{B}=1000$. Each project has two characteristics: its grade (either $A$ or $B$ ), which is drawn independently with equal probability, and the status quo subsidy, $s_{i}$, which is drawn independently from a uniform distribution with support $(0, \mathcal{B})$. The program manager's preferences are characterized by a fixed equivalence rule $e_{B}$ which indicates that $e_{B}$ grade $A$ projects are equivalent to one grade $B$ project.

We wrote a VBA program for Microsoft Excel that draws the grade of each project and its parameter $s_{i}$ at random and then computes the two allocations, the status quo allocation and the allocation based on Proposal 1. This procedure is repeated 1000 times to obtain an empirical distribution of selected allocations ${ }^{9}$ for different equivalence rules $e_{B} \in\{0.3,0.5,0.7,0.9,0.99\}$.

The results of these simulations are presented in Figure 1 in the form of cumulative distribution functions, $F(x)$. There, $F(x)$ denotes the probability that Proposal 1 gives rise to a relative gain in the value of the selected allocation of $x$ or less. The value of an allocation is computed as $n_{A}+e_{B} n_{B}$, where $\left(n_{A}, n_{B}\right)$ denotes the number of $A$ and $B$ projects in the respective allocation. And the relative gain in value is computed by dividing the increment in value due to switching from status quo allocation, $a^{s}$, to the allocation based on Proposal $1, a^{p}$, by the value of the status quo allocation, $a^{s}$.

Evidently, the relative value gains increase, in the sense of first-order stochastic dominance, if $B$ projects become more valuable relative to $A$ projects. This is plausible, because giving absolute priority to type $A$ projects, as the status quo preference rule does, becomes more costly as projects become closer substitutes.

\section{EXPERIMENTS}

In order to test the two auction mechanisms we set up a series of computerized lab experiments. ${ }^{10}$ There, subjects were assigned to play the role of a firm that applies for an R\&D subsidy. They either participated in the sealed-bid or in the open descending-bid mechanism. In the experiment, we used a simple grading scheme for projects as proposed above, with only two grades.

\footnotetext{
${ }^{9}$ That program code is available upon request from the authors.

${ }^{10}$ For instructions and screenshots see Giebe et al. (2005).
} 


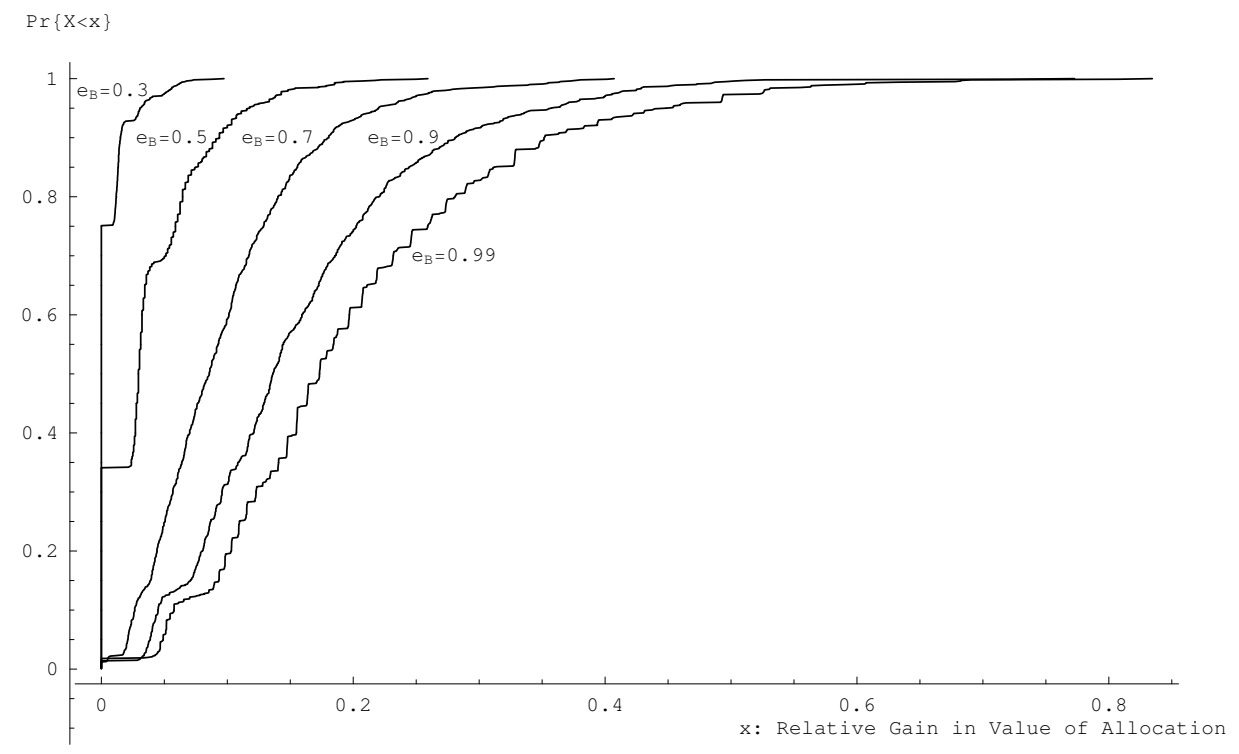

Figure 1: CDFs of relative value gains due to Proposal 1

\subsection{Experimental Design}

In the experiment, we formed groups of six subjects participating in one of the two mechanisms. Prior to the auction, each subject $i$ was given the following private information $\left(z_{i}, \pi_{i}, s_{i}, g(i)\right)$ :

1. the minimum subsidy needed to execute one's project, $z_{i}$;

2. the private profit earned in addition to the subsidy if one's project is executed, $\pi_{i}$;

3. the maximum (resp. starting) bid, $s_{i}$;

4. the grade of one's project, $g(i)$, either $A$ or $B$.

The smallest monetary unit was 1 ECU (experimental currency unit).

Each subject was informed that $\left(z_{i}, \pi_{i}, s_{i}\right)$ were independently drawn from uniform distributions with supports $z_{i} \in\{0,1, \ldots, 5\}, \pi_{i} \in\{0,1, \ldots, 10\}$, $s_{i} \in\{5,6, \ldots, 10\}$, and that there would be three grade- $A$ and three grade- $B$ projects, assigned to subjects with equal probability.

The following information was given to all subjects:

1. the budget $\mathcal{B}=20$,

2. the preference ranking over possible allocations:

$$
\begin{array}{rlrlrl}
\{A, A, A, B, B, B\} & \succ & \{A, A, A, B, B\} & \succ & \{A, A, B, B, B\} \succ \\
\{A, A, A, B\} & \succ & \{A, A, B, B\} & \succ & \{A, B, B, B\} \succ \\
\{A, A, A\} & \succ & \{A, A, B\} \succ & & \succ A, B, B\} \succ \\
\{B, B, B\} & \succ & \{A, A\} \succ & \succ A, B\} \succ \\
\{B, B\} \succ & \{A\} \succ & & \succ B\} .
\end{array}
$$


In the sealed-bid auction subjects were asked to enter their requested subsidy, $b_{i}$, referred to as "bid" in a computer screen window. After all bids were submitted, the software computed the best feasible allocation, based on the above preference ranking, according to the rules described in section 4. Those subjects who were part of the allocation received a credit equal to $b_{i}+\pi_{i}$ ECU; all others received no credit.

The open descending-bid auction was set up as a clock auction. There, each subject had its own price clock, starting at the maximum bid $s_{i}$ and decreasing at the fixed rate of one ECU per round. In each round, we first asked the grade- $A$ subjects to make simultaneous bids; then, all grade- $B$ subjects observed the bids of all $A$ subjects, and made their own simultaneous bids. There, a bid means that one either freezes the current reading of one's price clock or accepts a reduction by one ECU. This procedure continued until all subjects had stopped their price clock.

A subject who stopped its price clock in one round was not able to "unfreeze" it later. In each round, the active grade- $A$ subjects could see the current reading of the price clocks of all subjects and who had already stopped its price clock in which previous round and at which price. Similarly, the active grade- $B$ subjects could see the current reading of the price clocks of all subjects, which subjects had stopped in previous rounds, and, in addition, which grade- $A$ subjects stopped in the current round.

When all subjects had stopped their price clock, the final bids $b$ were the levels at which the individual price clocks had been stopped; the auction ended, and the software computed the best feasible allocation by the same rule as in the sealed-bid auction. Those subjects who were part of the allocation earned a credit of $b_{i}+\pi_{i}$ ECU; all others received no credit.

\subsection{Experimental Procedure}

The experiments were conducted in November 2003 at the Department of Economics, Humboldt University at Berlin. The subjects were 96 student volunteers. They were recruited by advertisements in lectures and by mail shots. Most of them were undergraduate economics or business students.

The treatments were computerized using the experimental software "z-tree" developed by Fischbacher (1999).

We conducted eight sessions. Four sessions were dedicated to the sealedbid auction, and another four sessions to the open descending-bid auction. In each session there were twelve distinct subjects.

Instructions and Trial Auction After being seated at a computer terminal, subjects were given written instructions including a detailed example.

In the instructions we referred to an allocation as a "combination," to a subsidy as a "grant," and to an applicant as a "bidder" in order to keep the terminology as neutral as possible without making it unduly difficult to 
understand the mechanism. We made clear that all decisions would be taken anonymously and that identities would not be revealed.

Two control questions checked whether the instructions were understood by all subjects. These control questions were computerized, with feedback for incorrect answers. Then, a "trial auction" was played which did not count for earnings.

Assignment of Subjects to Payoff-Relevant Auctions A session consisted of two parallel sequences of five auctions, each played by six subjects. After each auction subjects were randomly and anonymously reassigned to one of the two groups playing the next auction.

After each auction subjects were privately informed about their earnings. In order to reduce path dependencies, subjects were not told which allocation was selected.

At the end of the session subjects got a summary account of their earnings, and earnings were paid, including a show-up fee.

Payoffs A typical sealed-bid session took 40 and an open descending-bid session 90 minutes. Each subject's earnings in ECU were converted into $€$ at the rate $9 \mathrm{ECU}=€ 1$; in addition, subjects earned a show-up fee of $€ 4$ in a sealed-bid and $€ 10$ in a descending-bid session.

In sealed-bid sessions earnings were between $€ 5.90$ and $€ 11$, with an average of $€ 8$.40, and in the open descending-bid sessions between $€ 11.70$ and $€ 17.40$, with an average of $€ 14.40$.

\section{RESULTS}

Altogether, 96 subjects participated in 8 sessions with a total of 78 payoffrelevant auctions. ${ }^{11}$ The trial auctions are not considered in our analysis. As groups were rematched in every auction, subjects were able to learn from each other's behavior. Because of this, the results within a session are not independent. Hence, each treatment consists of 4 independent observations, one per session.

Since the set of independent observations is relatively small, we perform a mainly descriptive data analysis.

Of course, each auction resulted in one of the allocations stated in equation (5). These allocations are ranked by assigning a number $r \in\{1, \ldots, 15\}$, where $r=1$ stands for $\{A, A, A, B, B, B\}, r=2$ for $\{A, A, A, B, B, B\}$, etc. For convenience of notation we refer to the rank of the implemented allocation

\footnotetext{
${ }^{11}$ Actually, 80 auctions took place. However, due to a network problem, the data of 2 of the open descending-bid auctions were lost. Subjects were only informed after the experiment. They received a lump-sum payment of $€ 2$ for the third auction where the problem occurred. We therefore think that the data from the remaining auctions can be analyzed.
} 
as $r^{*}$, that of the optimal allocation as $r^{o}$, and that of the allocation that would be implemented if all bids were equal to the maximum bids as $r^{p}$.

As it happened, the optimal allocation was $\{A, A, A, B, B, B\}$ in 70 of the 78 auctions and $\{A, A, A, B, B\}$ in the remaining eight auctions.

Table 2 indicates which allocations were implemented in the experiments.

\begin{tabular}{l|cc|cc}
\hline \hline Allocations & \multicolumn{2}{|c|}{ Sealed-Bid } & \multicolumn{2}{c}{ Open Descending-Bid } \\
(ordered by rank $r$ ) & Frequency & $\%$ & Frequency & $\%$ \\
\hline $1:\{A, A, A, B, B, B\}$ & 3 & 7.5 & 6 & 15.8 \\
$2:\{A, A, A, B, B\}$ & 22 & 55 & 20 & 52.7 \\
$3:\{A, A, B, B, B\}$ & 6 & 15 & 3 & 7.9 \\
$4:\{A, A, A, B\}$ & 8 & 20 & 9 & 23.7 \\
$5:\{A, A, B, B\}$ & 1 & 2.5 & 0 & 0 \\
\hline \hline
\end{tabular}

Table 2: Frequency Distribution of Implemented Allocations

The further presentation and interpretation of the experimental results is ordered by the following hypotheses:

1. The auction improves the allocation: We explore to what extent the allocation improves relative to the allocation that would be reached if one adopted our Proposal 1 but not also Proposals 2 and 3.

2. The auction is almost efficient: We explore how close the observed allocations are to the corresponding optimal allocations.

3. "Handicapped" bidders play more aggressively: We explore whether and if so to what extent grade- $B$ bidders bid lower.

4. Higher private profits give rise to more aggressive bidding: We explore whether and if so to what extent bidders with a higher private profit submit lower bids.

5. More experience gives rise to more aggressive bidding: We explore whether bidders bid lower in later auctions in the sequence after gaining some experience.

Improvement due to the auction Figure 2 indicates that competition is effective. Bids are, on average, substantially below the maximum bids. Approximately $33 \%$ of all bids are even equal to the respective minimum bids. Average bids are slightly lower in the open descending-bid mechanism. ${ }^{12}$ Therefore, both mechanisms induce a remarkable intensity of competition.

We measure the improvement due to the auction by computing the average difference between the rank $r^{p}$ and that of the implemented allocation, $r^{*}$, i.e., $\left|r^{*}-r^{p}\right|$. In the sealed-bid mechanism that measure is equal to 5.78

\footnotetext{
${ }^{12}$ Wilcoxon Rank-Sum tests using the difference in average bids in the two mechanisms $(n=8)$ confirm our result on the $10 \%$-significance level.
} 


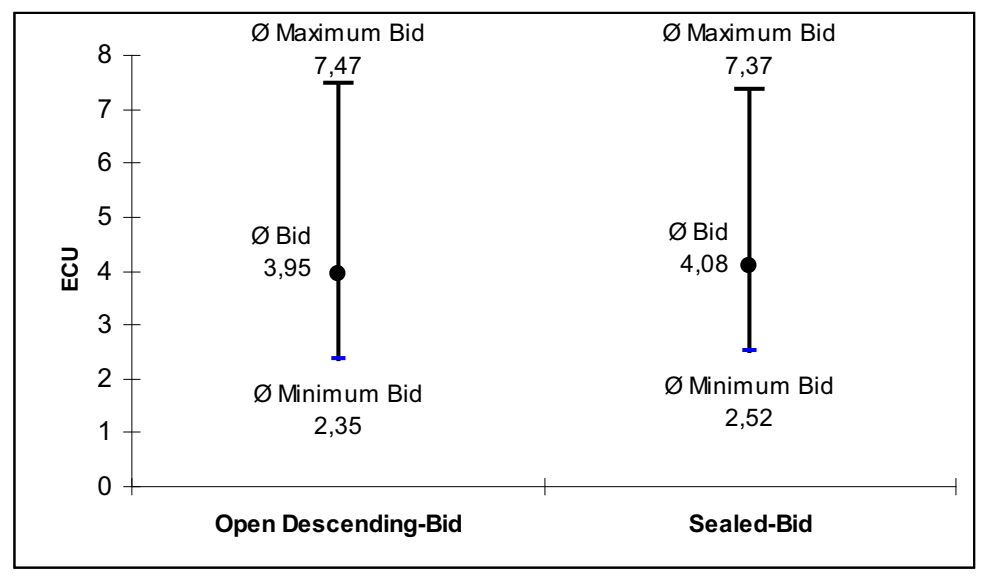

Figure 2: Average Bids

and in the open descending-bid mechanism equal to $5.89 .^{13}$ On average the auction increases the number of subsidized projects, relative to the allocation $a^{p}$, by 2.04. This indicates that adding the auction brings about a remarkable improvement.

Efficiency We call the outcome first-best if an auction implements the allocation $a^{o}$, i.e., if $r^{*}=r^{o}$. Similarly, we call it second-best or higher if $r^{*}=r^{o}+1$ resp. $r^{*}>r^{o}+1$.

We measure the deviation from the first-best by computing the average difference between the ranks of the optimal and the implemented allocations, $r^{*}-r^{o}$. In the sealed-bid mechanism that measure is equal to 1.45 and in the open descending-bid mechanism 1.31. This indicates that the auctions implement allocations that are close to the efficient ones.

Figure 3 summarizes the efficiency properties of both mechanisms. Without the auction, the implemented allocation would have been, on average, 8thbest. Thus, the deviation from efficiency is considerably smaller than the deviation from the allocations that would be reached without the auction.

"Handicapped Bidders" Figures 4 and 5 show that grade- $A$ applicants bid higher on average. This applies to all eight sessions. Specifically, in the sealed-bid auction, grade- $A$ bidders bid $27 \%$ higher on average and in the open descending-bid auction $12 \%$ higher. $^{14}$

Private Profits Intuitively, higher private profits should induce lower bids because those bidders should care more about getting the minimum fund-

\footnotetext{
${ }^{13}$ The average difference between $r *$ and the rank of the status quo allocation, i.e., the allocation that would be reached without using any of our proposals, is 6.1 on average.

${ }^{14}$ Wilcoxon Signed-Rank Tests $(n=4)$ confirm these results for both mechanisms on a 5\%-significance level.
} 


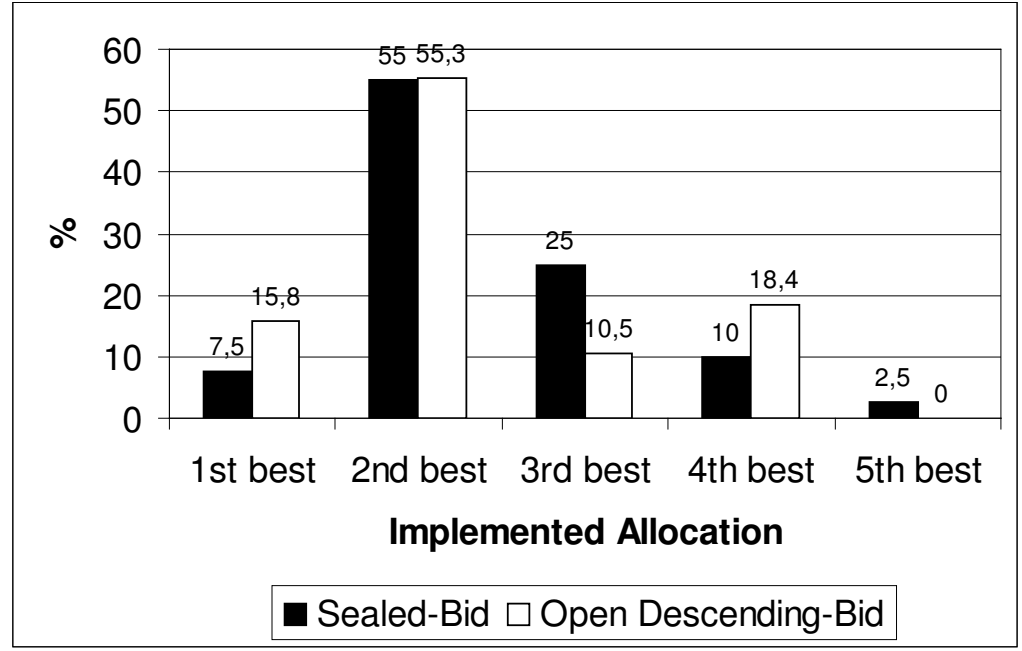

Figure 3: Efficiency Results

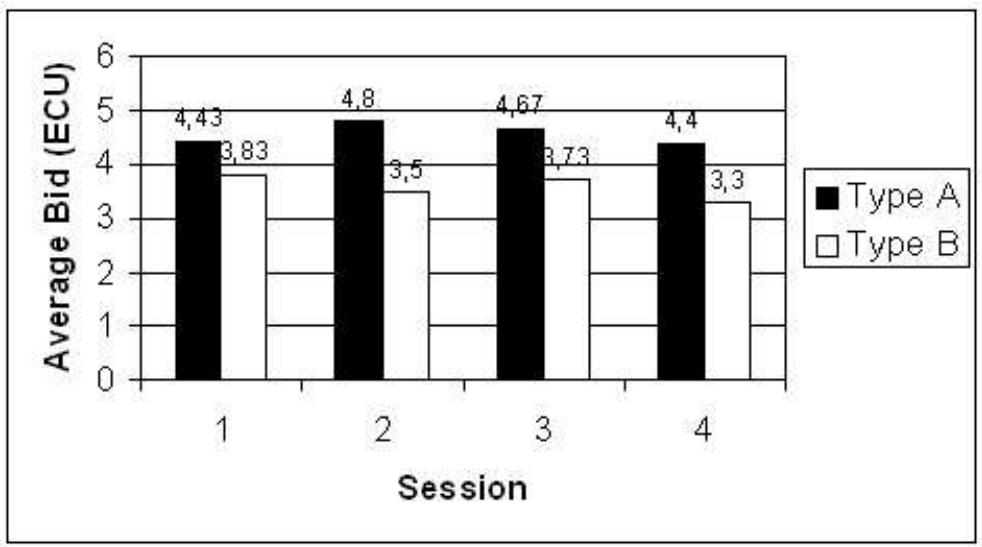

Figure 4: Average Bids in the Sealed-Bid Mechanism

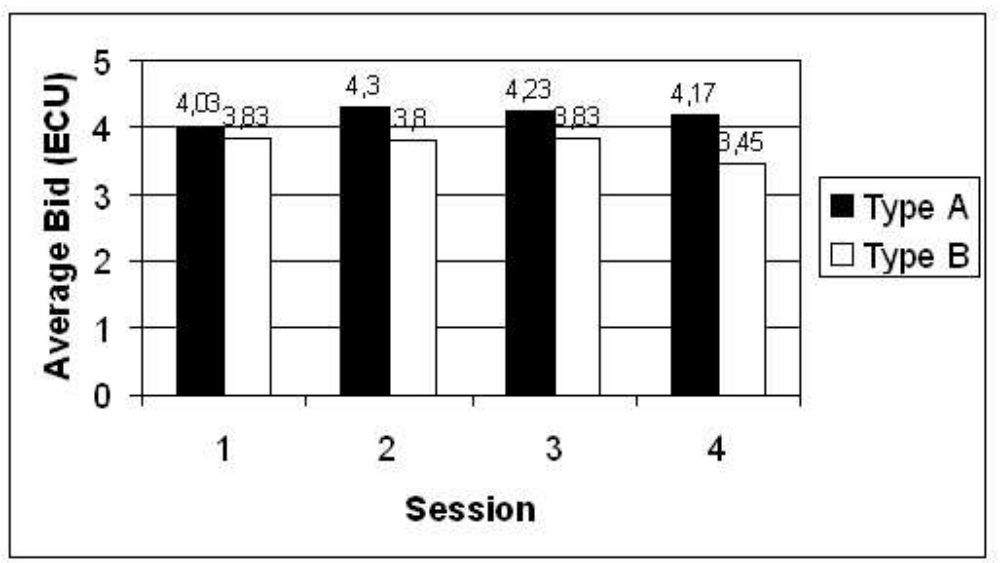

Figure 5: Average Bids in the Open Descending-Bid Auction 


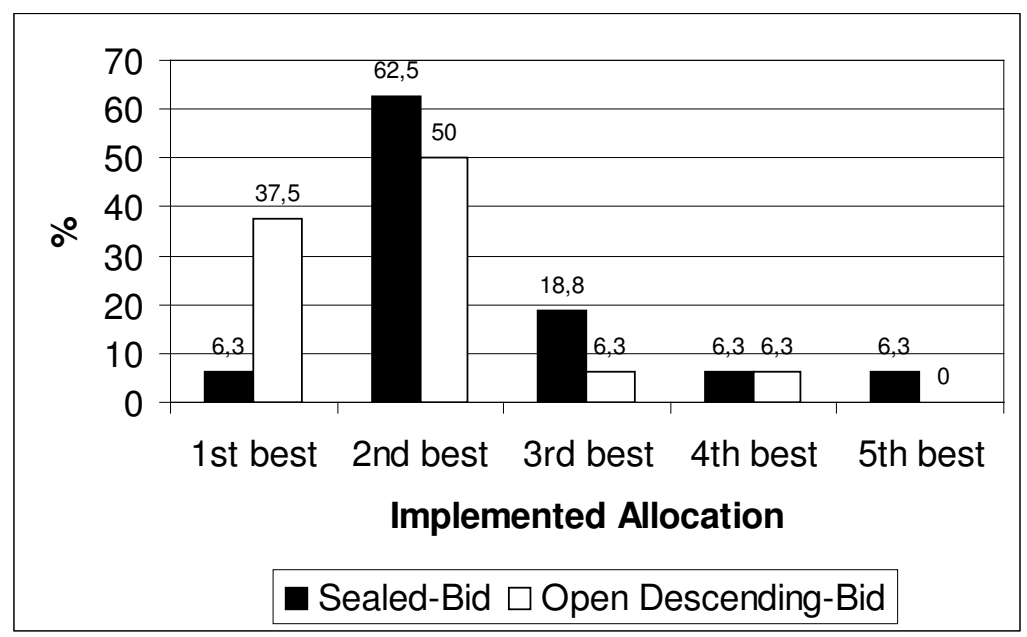

Figure 6: Efficiency in Late Auctions

ing needed to get their project off the ground, rather than about collecting unnecessarily high subsidies.

The coefficients for the correlation between private profit and the bid are $\rho_{\pi, b}=-0.1$ for the sealed-bid mechanism and $\rho_{\pi, b}=-0.15$ for the open descending-bid mechanism. The negative sign does indeed confirm this conjecture. However, the observed correlation is rather weak.

Experienced Bidders In the sealed-bid mechanism, average bids remain fairly stable during a session. However, in the open descending-bid mechanism the average bid in the first auction of each sequence is $15.7 \%$ higher than in the final one. From the fact that in the first rounds, bids across mechanisms are fairly similar and that the additional information given in the open descending bid mechanism (maximum bids of other bidders) does not have a significant impact on bids (correlation coefficients are near zero and unsystematic), we conclude that the improvement in the open descendingbid mechanism is due to experience from observing the behavior of other bidders.

Figure 6 states the outcomes of the fourth and fifth auction of each sequence, i.e., after bidders have acquired some experience. It indicates that experience induces more competitive bidding, resulting in a higher degree of efficiency. However, this improvement due to experience is more pronounced in the open descending-bid mechanism. ${ }^{15}$

\footnotetext{
${ }^{15}$ A Wilcoxon Signed-Rank test on the $5 \%$-significance level $(n=4)$ confirms our result: For the open descending-bid mechanism, bids during the first two auctions of each sequence are significantly higher than in the final two. For the sealed-bid mechanism, the hypothesis of significantly higher bids in the first two auctions of each sequence is rejected. Our observations are based on only 32 "late" auctions, 16 per treatment. A more extensive series of experiments would be required to check the robustness of these results.
} 
Not surprisingly, players lower their bids after they lose an auction. This learning effect is particulary strong in the sealed-bid auction. In fact, after losing an auction bids are on average reduced by $33.7 \%$ in the sealed-bid auction and by $16.7 \%$ in the open auction. And $73.7 \%$ of all losers respond in this way in the sealed-bid and $62.5 \%$ in the open auction.

\section{SUMMARY}

The present paper analyzes the allocation of subsidies to fund socially valuable projects that are not feasible without subsidy. Applications range from R\&D subsidies to the funding of charitable projects and academic fellowships. Typically, these allocation decisions are based on a ranking of individual projects, and subsidies are awarded successively to the best projects until the budget is exhausted. Thereby, the awarded subsidies are often a lump-sum payment or a fixed share of the estimated project cost.

We identify two sources of inefficiency of the commonly used funding procedures and propose better mechanisms that may remedy them. The highlights of our proposals can be summarized by two recommendations, the first of which can be implemented without the second:

- Select projects on the basis of a ranking of complete allocations rather than on a ranking of individual projects, possibly using a simplified ranking procedure.

- Induce applicants to reveal information about their true need for funding and use that information. This can be done by employing some form of an auction in which applicants bid for subsidies.

Ideally the first proposal involves using a complete ranking of allocations. But this is generally too complex. Therefore, we recommend the use of simple grading schemes, combined with fixed equivalence rules. This will generally improve the allocation relative to the currently used selection procedure (which implicitly assumes lexicographic preferences) without raising the level of complexity.

We test the first proposal by means of a Monte Carlo Simulation. We show that especially if projects are close substitutes, a ranking of allocations brings about a substantial efficiency gain compared to the currently used ranking of individual projects.

As for the second proposal, two specific auction mechanisms are tested in a controlled lab experiment. In our experiment, both mechanisms implement a high level of competition between applicants and thus lead to a substantial efficiency gain which becomes stronger as bidders gain experience. Thereby, the highest efficiency gains are realized by adopting an open descending-bid mechanism. 


\section{DISCUSSION}

Whilst quality competition for Subsidies is already commonly applied and accepted (see e.g. Eickelpasch and Fritsch (2005)), significant doubt has been expressed by program managers regarding the proposed extension of competition between applicants to the dimension of money. However, our results suggest that adopting our proposals may give rise to substantial improvements. Put differently, assessing quality independently from its cost makes no sense and produces inefficiencies.

However, we must stress that we evaluate the impact of our proposed mechanisms assuming a given set of projects. This ignores that the proposed change in selection rules may affect the proposed projects. If applicants anticipate that they compete not only in terms of project quality but also in terms of the requested amount of funding, they may propose different projects that are better targeted to the preferences of the selection committee. The fear was expressed that this may lead to projects with lower quality. However, we must stress that we do not propose to neglect quality in the assessment of projects. The weighting of quality and price for the assignment of subsidies can be set according to program manager's preferences, e.g. by designing appropriate grade and equivalence rule schemes.

Of course, if contracts are incomplete, firms may not live up to what they have proposed in the application. Program mangers often expressed the concern that this danger increases with a decreasing subsidy. However, we think that due to the close monitoring of firms in the current system this problem can be solved, e.g. by agreeing on fines for the case of noncompliance. Moreover, we doubt that the implementation of our proposals and the associated reduction of subsidy rates can be causal for such problems. The reason is that the incentive to downgrade the proposed project and to divert parts of the subsidy to other, possibly more profitable, activities, is already present in the current system. The underlying problems of contracting and monitoring must be addressed, but this has little if any relation to our proposals.

Another issue is that our proposals may lead to an increased number of funded projects, at a lower average level of reimbursed project costs. This means that the ex ante expected payoff from participating in the program does not change for the firms as long as the program budget is kept constant. However, administrative costs may increase because more projects are funded and thus more projects have to be administered and supervised.

Eickelpasch and Fritsch (2005) have criticized the current pure quality competition for its inability to support less able applicants, e.g. in lagging regions. Our approach is at least partly able to correct this flaw in that it increases the chances for lower quality projects to receive funding, albeit at a lower rate of subsidization.

Despite its obvious flaws, administrators are probably reluctant to change the current selection procedure. From our experience we see two main reasons. First, program managers are not aware of the obvious flaws, and are 
not trained to think in terms of allocations. Second, the current practice gives them considerably more leeway. No one can be expected to give up such power on his own initiative. Therefore, the policymaker must be reminded to exercise his power to make rules, and not delegate it to those who execute them. Unfortunately, this obvious principle is frequently violated in the public sector.

Results from an opinion survey conducted among German firms that have applied for a subsidy in the past, suggest that the majority of firms would be ready to accept proposals as made in this paper ${ }^{16}$. Remarkably, acceptance among small firms and those with a low equity endowment is strongest. We note, however, that the acceptance of an open mechanism is weaker. This may be due to the fact that it reveals private information not only to the auctioneer but also to competitors. We therefore think that especially in a framework where several competing firms participate in the same auction, the use of closed mechanisms may be more advisable because this avoids the mentioned problem.

\section{REFERENCES}

BECKeR, C., R. BIERHAls, K. Blind, S. EKeRT, T. GIEBE, T. GReBE, AND E. WOLFSTETTER (2004): Effizienzsteigerung bei der FuE-Projektförderung durch wettbewerbliche Vergabeverfahren, Report for the German Ministry of Economics and Labor. ${ }^{17}$

BENOÎT J.-P., AND V. KRISHNA (2001): "Multiple-object auctions with budget constrained bidders," Review of Economic Studies, 68, 155-179.

Binks, M., A.LocketT, D.Siegel And C. Wessner (2003): "Policies Promoting Innovation in Small Firms: Evidence from the U.S. and U.K,” Small Business Economics, 20, 121-127.

Blum, U., H. Bertheid, U. Draugelates, A. Kleinknecht, W. LeOnhardt, W. RUHRMANN, H. SCHEIBNER, AND M. WECK (2001): Endbericht der Kommission "Systemevaluation der Wirtschaftsintegrierenden Forschungsförderung," Report for the German Ministry of Economics and Labor. ${ }^{18}$

BLUM, U. AND F. KaLUS (2003): "Auctioning public financial support incentives," International Journal of Technology Management, 26 (2/3/4), 270276.

Che, Y.-K., AND I. GALE (1998): "Standard Auctions with Financially Constrained Bidders,” Review of Economic Studies, 65, 1-22.

\footnotetext{
${ }^{16}$ For more details and results of the opinion survey, see Becker et al. (2004) (only available in German).

${ }^{17} \mathrm{http}: / /$ www.wiwi.hu-berlin.de/wt1/papers/index.html

${ }^{18}$ http://www.bmwi.de/Redaktion/Inhalte/Pdf/S-T/systemevaluation-derwirtschaftsintegrierenden-forschungsfoerderung-systemevaluation,property=pdf,bereich=,sprache=de,rwb=true.pdf, an english summary is available at http://www.bmwi.de/English/Redaktion/Pdf/systemevaluation-of-industry-integrating-research-assistance,property=pdf,bereich=,sprache=de,rwb=true.pdf
} 
CZARnitzKI, D., AND G. LICHT (2005): “Additionality of Public R\&D Grants in a Transition Economy: The Case of Eastern Germany," Economics of Transition, forthcoming.

CZARnitZKI, D., AND A. FIER(2001): “Do R\&D Subsidies Matter? - Evidence for the German Service Sector," ZEW Discussion Paper No. 01-19, Mannheim ${ }^{19}$

EICKELPASCH, A. AND M. FRITSCH (2005): "Contests for cooperation-A new approach in German innovation policy,” Research Policy, 34(8), 1269-1282.

FISCHBACHER, U. (1999): Z-Tree. Zurich Toolbox for Readymade Economic Experiments - Experimenter's Manual, Working Paper 21, University of Zürich.

García-Quevedo, J. (2005): “Do Public Subsidies Complement Business R\&D? A Meta-Analysis of the Econometric Evidence,” Kyklos, 57(1), 87-102.

Giebe, T., T. Grebe AND E. Wolfstetter (2005): “How to Allocate R\&D (and Other) Subsidies: An Experimentally Tested Policy Recommendation - Instructions and Screenshots from the Lab Experiment", HumboldtUniversity at Berlin. ${ }^{20}$

LAFFONT, J.-J., AND J. ROBERT (1996): “Optimal Auction with Financially Constrained Buyers,” Economics Letters, 52, 181-186.

MARTIN, S., AND J. T. SCOTT (2000): “The Nature of Innovation Market Failure and the Design of Public Support for Private Innovation," Research Policy, 29, 437-447.

TRAJTENBERG, M.(2002): “Government Support for Commercial R\&D: Lessons from the Israeli Experience," in A. Jaffe, J. Lerner and S. Stern (eds.), Innovation Policy and the Economy, Vol. 2, National Bureau of Economic Research, MIT Press, 2002.

\footnotetext{
${ }^{19} \mathrm{ftp}: / /$ ftp.zew.de/pub/zew-docs/dp/dp0119.pdf

${ }^{20}$ http://www.wiwi.hu-berlin.de/wt1/papers/index.html
} 